\title{
Reserve prices as reference points - Evidence from auctions for football players at hattrick.org *
}

\author{
Stefan T. Trautmann \\ Tilburg Institute for Behavioral Economics Research \& CentER, Tilburg University, \\ The Netherlands \\ Christian Traxler \\ Max Planck Institute for Research on Collective Goods, Bonn, Germany
}

February, 2009

\begin{abstract}
We study the impact of sellers' reserve prices on transfer prices in online auctions of virtual football players. We introduce an empirical model that distinguishes two separate effects from public reserve prices: (1) a mechanical effect, which is driven by the design of the English auction and (2) a psychological reference-dependence effect through reserve prices serving as reference points. The psychological effect has recently been introduced in behavioral models of situations where agents are uncertain about their own willingness-to-pay, while the mechanical effect is well captured by standard auction theory. Controlling for censoring when players are not sold, both effects are observed. Once we account for the potential endogeneity of reserve prices, however, we do not find evidence for reference dependence in Hattrick auctions.
\end{abstract}

Keywords: Reserve prices, Reference dependence, Auctions, Online games JEL classification: D12, D44, C24

\footnotetext{
${ }^{*}$ Corresponding Author: Stefan Trautmann (Tel.: +31 1346633 90, Fax: +31 13466 20 67). E-mail addresses: trautmann@uvt.nl (S.Trautmann); traxler@coll.mpg.de (C. Traxler). We thank Alpaslan Akay, Maarten Boksem, Susan Dynarski, Theo Offerman, as well as seminar participants in Barcelona and Innsbruck for helpful suggestions. Stefan Trautmann gratefully acknowledges financial support from the Vereniging Trustfonds Erasmus Universiteit Rotterdam.
} 


\section{Introduction}

Reference dependence is an important factor in decision making. Its role is empirically well established for individual choice situations and it has successfully been modeled through prospect theory (Kahneman, 2003). Less is known about the effects of reference dependence in real-world markets. A central problem in all applications of reference dependence concerns the choice of the reference point (Bleichrodt, 2007; Lin, Huang, \& Zeelenberg, 2006; Sayman \& Öncüler, 2005; Schmidt, 2003), and market situations usually offer a number of possible candidate points. List prices, other persons' valuations, or prices of alternative products may serve as reference points for the agent's valuation of a product. In particular, reference point effects will be relevant if agents are uncertain about their own willingness-topay and therefore construct valuations in an environment with external cues (Kristensen \& Gärling, 1997; Rosenkranz \& Schmitz, 2007; Stern \& Stafford, 2006).

Markets where reference points would be expected to exert a strong influence on decisions are the rapidly growing online auction platforms like eBay or uBid. On these auction websites consumers and businesses sell to consumers directly, substituting for traditional intermediaries. Buyers face a complex environment with competition, changing prices, minimum bids, buy-it-now options and time pressure. In this environment it is conceivable that cues provided within the auction process influence the buyers' valuation and bidding behavior.

A recent theoretical analysis by Rosenkranz and Schmitz (2007) considers the seller's public reserve price (minimum bid) as a possible reference point that influences buyers' willingness-to-pay in auctions. In their model, a higher price not only reduces the buyers' surplus, it also triggers an additional disutility, which is increasing in the disparity between the price paid and the seller's reserve price. The buyers' valuations therefore depend on the publicly announced reserve price, and a higher reserve price will ceteris paribus raise the consumers' willingness-to-pay because it reduces this disparity.

The empirical evidence for this reference point effect, which is discussed in Section 2 of the paper, is inconclusive. Ariely and Simonson (2003), Kamins, Drèze, and Folkes (2004), and Stern and Stafford (2006) show positive effects of reserve prices on selling prices in field data and in field experiments. Bajari and Hortacsu (2003) find no evidence for reference dependence in their field study. Hoppe and 
Sadrieh (2007) conduct a field experiment and find no evidence either. Our paper adds to the literature by introducing an empirical model that distinguishes between psychological and economic reserve price effects, and by testing for these separate effects in an environment that eliminates the potentially confounding effects from signaling quality and trustworthiness.

When studying consumer behavior with real products on eBay and similar platforms, signaling through reserve prices cannot easily be controlled. Buyers cannot verify the quality of the product ex-ante, introducing uncertainty and asymmetric information between buyers and sellers. Apart from private values for the product based on some fixed quality ${ }^{1}$, a common value component and a winner's curse problem become relevant. The winner's curse refers to the fact that the bidder with the highest estimate of quality is likely to hold a too positive view of the true but unobservable quality (common value), which then forms the basis of private valuations of the product. In such an environment reserve prices can serve as quality signals and therefore influence bids even in the absence of reference dependence. The importance of trust and reputation in online auctions further aggravates the scope for signaling (Resnick, Zeckhauser, Swanson, \& Lockwood, 2006).

We overcome all problems associated with quality uncertainty by studying reserve and selling prices for virtual football players traded in English auctions on hattrick.org. Hattrick is the world's largest online football manager game with almost one million participants. Every day several ten thousand players are traded on the Hattrick transfer market. Sellers can choose a non-negative reserve price (public minimum bid). When Hattrick players are on the market, all relevant information concerning their quality becomes publicly available. That is, there is no information asymmetry between buyers and sellers. Reserve prices cannot contain any quality signal and there is neither scope for winner's curse or for concerns regarding the sellers' trustworthiness. In Section 3 we discuss the auction market in Hattrick in detail. There we also explain how the success in this open-ended manager game crucially depends on successful trading of the participants. ${ }^{2}$

\footnotetext{
${ }^{1}$ Note that an agent can be uncertain about her private valuation of the product even if the quality is observed and fixed.

${ }^{2}$ Two other papers study the Hattrick environment. Englmaier and Schmöller (2008) examine optimal search behavior in the Hattrick market, and Ajalin, Granö, and Nyberg (2004) consider Hattrick football matches in their study on betting on virtual sports events.
} 
In our empirical model we distinguish between the behavioral reference point effect discussed above, and a mechanical effect as predicted by auction theory (RileySamuelson, 1981). In second price auctions like those on eBay and Hattrick, the price paid by the highest bidder corresponds to the second highest bid (increased by one bidding increment). If the reserve price falls between the highest and the second highest bidder's valuation, however, there is only one bidder. The price is then given by the reserve price. In this case, the selling price "mechanically" increases with a higher reserve price. Note that this effect is entirely driven by the auction design and occurs irrespectively of any reference-dependent utility effect.

We use data on 364 football players that were posted on the transfer market to study the effect of publicly announced reserve prices, and we identify both the reference point and the mechanical effect of the reserve prices. Our approach also accounts for two technical problems that have received little attention in empirical studies of reserve prices: first, we control for censoring, i.e. the fact that high reserve prices might result in items not being traded. Second, we consider the potential endogeneity of the reserve price. In this vein, we examine whether neglecting censoring and endogeneity problems can lead to a biased assessment of the reserve price effects.

A detailed discussion of our empirical strategy and the data is provided in Section 4. The results are presented in Section 5. Section 6 discusses the results, relates them to the literature, and considers potential problems of our approach. The concluding section shows how the results from virtual football can inform us about the interaction of behavioral and market effects in the pricing of football players in real world markets. In particular, we discuss which properties of the market for football players are-according to our results—likely to promote or mitigate reserve price effects, respectively. The section also considers avenues for future research in more controlled laboratory settings.

\section{Reserve prices as reference points: Review of the empirical literature}

The effect of reserve prices in auctions has been studied in field experiments, where the researcher sells items at different reserve prices on eBay, and in field studies using data from real auctions. One of the first studies was conducted by Ariely and Simonson (2003) who use both formats. In their field study Ariely and Simonson 
analyze the impact of reserve prices on the final price for college football tickets. They find that each dollar increase in the reserve price increases the sales price by 80 cents. The authors do not control for tickets for which there was only one bidder. Part of the observed reserve price effect might therefore be due to the mechanical effect caused by competitive reserve price setting. Ariely and Simonson do not discuss censoring or endogeneity problems.

In their field experiment Ariely and Simonson sell various items at either low or high reserve prices on eBay. In some auctions the same item was offered at both the high and the low reserve price simultaneously. They find a positive effect of the high reserve price on average bids, but only if there was no low reserve price item offered simultaneously. Although there were no unsold items, indicating modest reserve prices, some items might have been sold exactly at the reserve price. Hence, the effect could at least partially be driven by the mechanical effect of the second price auction rather than by reference dependence.

Kamins et al. (2004) sell sets of unsearched $\operatorname{coins}^{3}$ at either low or high reserve prices on eBay and find a positive effect on selling prices. There were bids exactly at the reserve price. Additionally, the items sold here carry considerable quality uncertainty, and the reserve price may convey a signal about whether the sets are indeed unsearched. For instance, bidders could perceive a high reserve price as a signal that the seller expects some valuable coins to still be in the set.

Stern and Stafford (2006) study field data from eBay auctions for a wide range of product categories. Not accounting for censoring, they consider only auctions that resulted in a sale and find a strong positive effect of sellers' reserve prices on transfer prices (65 cents increase in transfer price for each dollar increase in the reserve price).

There are two studies which find no effect of the reserve prices. The first is Hoppe and Sadrieh (2007), who study the link between reserve and selling prices for DVDs and coins on eBay. Their negative result is somewhat surprising, because there were many observations for items that sold at exactly the reserve price. For these observations, the mechanical effect should establish a positive effect of reserve on selling prices.

Bajari and Hartacsu (2003) study the uncertainty about product value and winner's curse in a sample of auctions for coins on eBay. They also assess the effect

\footnotetext{
3 "Unsearched" means that the seller has not searched and removed valuable coins from the set. The true value of the set should therefore be unknown to both sellers and buyers.
} 
of reserve on selling prices and find a positive effect in a simple OLS regression. The effect vanishes, however, once they control for censoring, i.e. high reserve prices preventing items from being traded.

The results of these studies are inconclusive regarding the psychological effect of reserve prices. The reference point and the mechanical effects have not been distinguished so far, and censoring and endogeneity may have affected the estimated effects (see Section 4). Reference dependence might have subtle effects that can not be identified in all samples, which could explain the negative evidence in the latter two studies. Similarly, the mechanical effect depends on the presence of competitive reserve prices and significant valuation differences between bidders. If the valuation difference between the highest and second highest bidder is small, there is little to gain from a competitive reserve price and the effect on selling prices will be negligible.

Asymmetric information about quality and trustworthiness, which allow reserve prices to convey signals, could have been a further confounding factor in previous studies. We will study both effects of reserve prices- the one deriving from a reference point in valuations and the one deriving from the mechanics of the auction-in a data set where there is no asymmetric information and thus no scope for signaling.

\section{Auctions for football players at Hattrick}

Hattrick is an open-ended football manager game played on the internet by roughly a million participants. ${ }^{4}$ Each participant owns a team that plays in one of many divisions in his country of residence. The goal is to promote to higher divisions and win the national championship and cup. Successful managers can become manager of the national team and play in the world cup against other national teams. A Hattrick season lasts 16 weeks in the real world. Although participation is free and there is no real money involved in the game itself, there are numerous costly add-on computer programs that can be purchased to assist the participants in the management of their teams. In addition, participants can become supporters of the online game by paying a yearly fee of $€ 25$. Becoming a Hattrick Supporter does not affect the game

\footnotetext{
${ }^{4}$ In this section only the features of Hattrick that are most relevant to our auction data are discussed. The complete game rules and more information about the Hattrick universe can be found at www.hattrick.org.
} 
but gives participants the possibility to design the website of the team according to their own preferences, as well as access to additional statistics and bookmarks.

Managers face a constrained budget in terms virtual money. Given this constraint, they have to make decisions about training and match orders, tactics and team psychology, the development of the club and the stadium, recruiting of youth players, and transfers. Virtual football players have a set of different skills which define their strength on a certain position within the team. The different skills are measured on numerical scales, and improving the players' skills by one increment takes several weeks of training. Each week only one specific skill can be trained. This training institution makes the transfer market a crucial aspect of the Hattrick universe: it is impossible to simultaneously develop skills for players on different positions. Managers therefore specialize on the training of one particular skill, say scoring, and thereby produce a constant stream of good forwards. These forwards are then sold on the transfer market. The proceeds from the sales are used to buy players for other positions, or to improve the club's stadium, etc. Revenues from player sales form the main source of virtual income for the club, together with income from sponsors and tickets sold for home games.

Each team manager has private information about all skills of his player. Once a player is posted on the transfer market, however, his skills become public information. Hence, there is no asymmetric information between buyers and sellers about players on the market. Of course, the value of a player for a potential buyer (private value) depends on his fit with this manager's team, the training and game strategy, as well as the team's position in the league. Consider for example the case of a manager who competes with another team for promotion in her league. Because promoting teams receive prize money and additional supporters, this manager might be willing to pay more for a player compared to a manager who is not currently involved in a promotion contest. Buying the player increases the chance of promotion and to quickly recover some of the cost, and therefore increases the acquiring manager's willingness-to-pay for the player.

Note that managers can rely on various computer programs, which can be purchased for real money, to assess the value of a player for the team. This assessment is noisy, however, because even with public knowledge of all player skills is it impossible to perfectly predict the consequences of a transfer. The manager's uncertainty about her private value from a player leads to a potential role for reserve 
prices to influence manager's willingness-to-pay through reference point effects. The Hattrick environment resembles real world markets for football players in this respect, where the sportive and therewith financial consequences from transfers are equally difficult to predict. The online platform therefore provides a controlled testing ground for behavioral theories of reserve price effects that potentially influence pricing in real transfer markets affected by value uncertainty.

The Hattrick transfer market is organized as a standard English auction with ascending open bids. Players are posted on the market and stay there for three days. ${ }^{5}$ A non-negative public reserve price can be declared for the player. Potential buyers can submit bids that are at least as high as the reserve price and higher than the current highest bid. The reserve price and the current highest bid with information about the bidder are shown next to the player information (see the screenshot in the Appendix). If bids are submitted in the last 3 minutes before the deadline, the deadline is extended by 3 minutes. The highest bidder wins the auction. The transfer price equals the second highest bid (increased by one bidding increment), or, if there was only one bid, the reserve price. If no bidder submits a bid which is at least equal to the reserve price, the player is removed from the transfer list after three days. All transfers of money and players are automatized. Hence, in contrast to, e.g., eBay, there is no scope for concerns about the trustworthiness of a seller to affect the transfer.

Participation in transfer auctions is a regular task for Hattrick team managers and they have a lot of experience in the market. We drew a random sample of hundred managers from the population of all managers and found an average number of 96 trades on either side of the market. That is, most managers have experience both as a seller and as a buyer.

\section{Empirical strategy and data}

Our sample consists of 364 players that were posted on the Hattrick transfer market. All players are "playmakers" with the strength classification "excellent" for playmaking, but variation on all other skill dimensions. These players have a score 8 on the numerical skill scale (ranging from 0 to 20), and are good enough to always provide positive market value. That is, they are tradable. At the same time, this class

\footnotetext{
${ }^{5}$ Putting a player on the transfer list involves a small fee that is negligible compared to the usual transfer prices for players.
} 
of players is also affordable to a large group of buyers. We observe all background and skill variables of the players, variables for the transaction (e.g. the day of the transaction) and the interaction between seller and player (e.g. tenure in the team), the reserve prices, and selling prices if the player was traded (see the Appendix for a list of all variables and explanations). For managers we observe their market experience (number of trades) and their Hattrick Supporter status.

The sellers in our sample have completed on average 149 trades and the buyers have completed 131 trades, considerably more than the average manager in the population. This is due to the fact, that we focus on a market segment (excellent playmakers), which is hardly accessible for inexperienced managers at the start of their career.

In our sample, sellers demand a positive reserve price for 313 players. Of these, 137 players $(44 \%)$ were not sold and $41(13 \%)$ were sold exactly at the reserve price (Table 1).

Table 1: Structure of the sample

\begin{tabular}{lrr}
\hline \hline All players & 364 & \\
Positive reserve price & 313 & \\
Sold for more than reserve price & & 135 \\
Selling price = reserve price & 41 \\
$\quad$ Not sold & & 137 \\
Zero reserve price (all sold at positive price) & 51 \\
\hline \hline
\end{tabular}

Our estimates of the effect of the reserve price on the transfer price are based on the following model:

$$
\text { transfer price }=\mathbf{X} \alpha+\beta \text { reserve price }+\varepsilon .
$$

The vector $\mathbf{X}$ contains all player characteristics and attributes of the auction (e.g. the day of the transfer), and $\varepsilon$ depicts the residual. The parameter of interest is $\beta$, which measures the extent to which a higher reserve price results in a higher transfer price, controlling for the quality of a player. Two possible channels contributing to a positive coefficient $\beta-\mathrm{a}$ psychological reference point effect and a mechanical effect from the auction design — are illustrated in Figure 1.

On the horizontal lines we measure the bidders' valuation for a given player. $\mathrm{H}$ and $\mathrm{S}$ denote the valuation of the highest and the second highest bidder, 
respectively. The dotted vertical line represents the reserve price. In Figure 1a the reserve price is relatively low. There is competition between bidders and the selling price is $\mathrm{S} .{ }^{6}$ Figure $1 \mathrm{~b}$ depicts the valuations for the same player, but at a reserve price that is $\Delta$ units higher than the one in Figure 1a. Given that the reserve price serves as a reference point and that it has a positive effect on valuations, $\mathrm{S}$ and $\mathrm{H}$ should be higher in Figure 1b than in Figure 1a. For simplicity we assume in Figure 1 that $S$ and $\mathrm{H}$ increase by the same amount. In the example, the increase in the reserve price by $\Delta$ raises the transfer price by $\beta$.

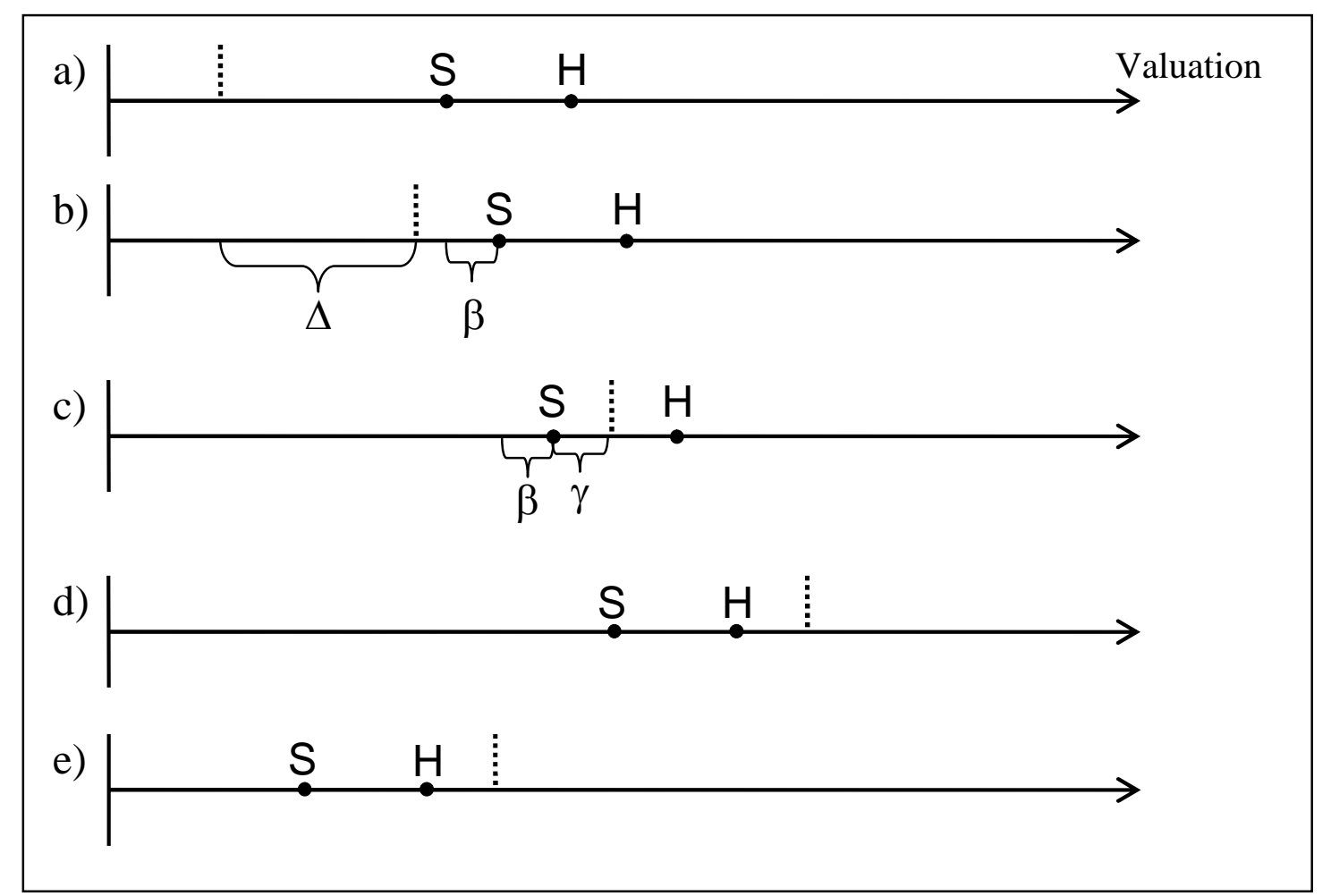

Note: Dotted vertical line: reserve price; S: second highest bidder's valuation; H: highest bidder's valuation

Figure 1: Reserve price as reference point

Now consider situation $1 \mathrm{c}$. The reserve price is increased by another $\Delta$, and it now falls between the highest and the second highest bidder's valuation. Again, there is the effect of reference dependence which raises valuations $\mathrm{S}$ and $\mathrm{H}$ by $\beta$. However, the selling price increases by more than $\beta$ in Figure $1 \mathrm{~b}$, because the highest bidder now pays the reserve price instead of S. Thus, there is a mechanical effect of the reserve price that simply follows from the auction design and not from reference

\footnotetext{
${ }^{6}$ Recall that the transfer price in this auction will be an increment above the second highest bid.
} 
dependence. In the example, the effect triggers an additional increase of the transfer price by $\gamma$.

To control for the mechanical effect in our estimation we include an additional slope parameter for those players for which there is only one bidder. Let the indicator $\mathrm{I}($ one $)$ equal one if there was exactly one bidder and zero otherwise. We then estimate the equation

$$
\text { transfer price }=\mathbf{X} \alpha+\beta^{\prime} \text { reserve price }+\gamma \mathrm{I}(\text { one }) \text { reserve price }+\varepsilon .
$$

In Eq. (2), the parameter $\beta^{\prime}$ measures the effect of reference dependence and the parameter $\gamma$ captures the mechanical effect. For auctions with only one bid, the total effect of the reserve on the transfer price is given by $\beta^{\prime}+\gamma$. For auctions with more than one bid there is no mechanical effect, and the total effect equals $\beta^{\prime}$.

The estimation of Eqs. (1) and (2) is complicated by censoring, because we do not observe the dependent variable, the transfer price, for all auctions, but only for those where the player was actually sold. The problem is illustrated in Figure 1d. The reserve price in this example is higher than the highest bidder's valuation. The observation does not preclude an effect of reference dependence: valuations are higher in Figure 1d than in Figure 1c, but not high enough to lead to a sale of the player at the higher reserve price.

There are situations, however, where censoring provides information against reference dependence. Such a situation is shown in Figure 1e. Assume that Figures 1a, $1 \mathrm{~b}$, and 1e depict valuations for three players that are identical in all attributes but differ with respect to their reserve price. Neglecting the unsold player le leaves us with strong evidence for reference dependence. The higher reserve price for player $1 \mathrm{~b}$ relative to 1a seems to have a positive effect on the selling price. If we take the censored observation 1e into account, however, the evidence becomes much less convincing. Despite a higher reserve price for player $1 \mathrm{e}$ than for $1 \mathrm{~b}$, the true unobserved market value must be smaller than the selling price of the player in $1 \mathrm{~b}$. Hence, this observation provides evidence against reference dependence.

Because the exclusion of censored observations could result in biased estimates of $\beta$ and $\beta^{\prime}$, we have to control for censoring in the regression analyses. Note that each player had an individual reserve price and therefore a different censoring point. We therefore use censored normal regressions, an extension of the 
Tobit model that allows for variable censoring points, to correct for censoring bias (Wooldridge, 2002).

The censoring problem and the mechanical effect potentially affect the results in all studies where reserve prices are set competitively. For all non-experimental studies, a further problem arises from the potential endogeneity of the reserve price. If the reserve prices that are set by the sellers reflect some quality of the player or the market that is observed by buyers and sellers but not by the researcher, any estimation of the reserve price effect would be biased. Neglecting unobserved factors that increase both reserve prices and willingness-to-pay inflates the coefficient for the reserve price.

Although we observe all player skills in our data, this problem can nevertheless occur. A potentially omitted variable is the name of the Hattrick player on the market. While the names are easily observable, it is difficult to control for the quality of these names in our analysis. If, for instance, a virtual player has a name that is similar to that of a popular real world football player, the seller might ask a higher price and buyers might be willing to pay more. Another source that can lead to endogeneity stems from unobserved demand constellations in the market. Certain player types with specific combinations of attributes may be perceived as particular valuable both by sellers and buyers If these combinations are not covered by our model (e.g. if there are complex interactions of player characteristics), the effect is taken up by the reserve price and we face a clear endogeneity problem.

To test and correct for endogeneity of the reserve price in our censored regression model we use the Smith and Blundell (1986) two-step procedure. The first step consists of a linear regression of the reserve price on all player attributes and instruments. In the second step the residuals of the first step OLS are included in the censored regression model. This procedure gives consistent estimates of all parameters of interest even in the presence of endogeneity of the reserve price. The tstatistic on the first-step residuals in the second step regression provides a test of the endogeneity.

As instruments we use three variables that are likely to affect the reserve price. These variables are (1) a dummy variable indicating whether the player comes from the seller's own youth team, (2) the number of years the player has been in the seller's team, and (3) the improvement of player (in terms of total skill) during his tenure on the team. None of these variables is easily observed by the buyers, and while they 
should not affect the buyers' valuations, it is likely that the seller's valuation is influenced by his knowledge about the player's history in his team.

\section{Results}

All regressions in this section include our full set of player, transaction, and manager attributes as controls. We report the effects of the reserve price and four key player attributes to study the effect of possible misspecification in our study. ${ }^{7}$ The player attributes that we report are the total skill index of the player, his age, his general form, and his weekly wage. These player attributes have clear expected effects on selling prices that are based on the economics of the Hattrick game rules. A higher score on the total skill index and the form have a positive influence on the player's strength and therefore make him more valuable. Increasing age reduces the speed at which the player's skills improve with training, thereby reducing his value to the owner (Englmaier \& Schmöller, 2008). Wages constitute the main costs for a team and therefore have ceteris paribus a negative effect on valuations.

We also report the effect of the managers' experience (number of trades) and the Hattrick Supporter status (measured by a dummy) for sellers. Note that the equivalent attributes for the buying manager can only be observed for those players that have been sold and therefore cannot be included in the Tobit regressions (see discussion in section 5.2.).

\subsection{Reserve price effects}

Ordinary least squares. Column I in Table 2 shows the results from an OLS regression of Eq. (1), based on those players for which we observe a transfer. This regression does not control for censoring or endogeneity of the reserve price, and it does not differentiate between the reference point and the mechanical effect of reserve prices. The estimation outcome shows a highly significant positive effect of the reserve price. The point estimate suggests that, holding constant all player characteristics, a $€ 1$ increase in the reserve price increases the transfer price by 68 cents. Counter intuitively, we find a weakly significant negative effect $(p=0.053$, one-

\footnotetext{
${ }^{7}$ The effect of player attributes is of no interest in itself. In contrast to studies using various products on eBay, however, player attributes are numerically defined and observable, and have unambiguous directions. They can therefore inform us about possible biases in the regression analyses.
} 
sided) of total skill on transfer prices, and a positive effect of wage costs on transfer price. There is no effect of the player's form on prices.

Table 2: Regression analyses — Determinants of the transfer price

\begin{tabular}{|c|c|c|c|c|}
\hline & (I) & (II) & (III) & (IV) \\
\hline $\begin{array}{l}\text { Dependent variable: } \\
\text { Transfer price }\end{array}$ & OLS & $\begin{array}{l}\text { Censored } \\
\text { normal } \\
\text { regression }\end{array}$ & $\begin{array}{l}\text { Censored } \\
\text { normal } \\
\text { regression }\end{array}$ & $\begin{array}{l}\text { Censored } \\
\text { normal } \\
\text { regression, } \\
\text { accounting for } \\
\text { endogeneity }\end{array}$ \\
\hline Reserve price & $\begin{array}{l}0.6808 * * \\
(0.1136)\end{array}$ & $\begin{array}{l}0.4856 * * \\
(0.0401)\end{array}$ & $\begin{array}{l}0.255^{* *} \\
(0.0554)\end{array}$ & $\begin{array}{l}-0.0878 \\
(0.1020)\end{array}$ \\
\hline $\begin{array}{l}\text { Reserve price } \times \text { one } \\
\text { bidder only }\end{array}$ & & & $\begin{array}{l}0.3870 * * \\
(0.0575)\end{array}$ & $\begin{array}{l}0.3578 * * \\
(0.05507)\end{array}$ \\
\hline $\begin{array}{l}\text { Residuals from first } \\
\text { stage regression }\end{array}$ & & & & $\begin{array}{l}0.3893 * * \\
(0.0959)\end{array}$ \\
\hline Total skill index & $\begin{array}{l}-7.4456 \\
(4.5657)\end{array}$ & $\begin{array}{l}6.8032 * * \\
(2.1071)\end{array}$ & $\begin{array}{l}1.8972 \\
(2.1479)\end{array}$ & $\begin{array}{l}11.2482^{* *} \\
(3.1280)\end{array}$ \\
\hline Age & $\begin{array}{l}-9341.388 * * \\
(3489.853)\end{array}$ & $\begin{array}{l}-12070.06^{* *} \\
(2665.863)\end{array}$ & $\begin{array}{l}-12875.95 * * \\
(2594.941)\end{array}$ & $\begin{array}{l}-15194.06 * * \\
(2563.816)\end{array}$ \\
\hline Form & $\begin{array}{l}4437.348 \\
(3729.368)\end{array}$ & $\begin{array}{l}9877.188 * * \\
(3695.059)\end{array}$ & $\begin{array}{l}10167.92 * * \\
(3606.466)\end{array}$ & $\begin{array}{l}11797.52 * * \\
(3491.202)\end{array}$ \\
\hline Wage & $\begin{array}{l}45.846^{* *} \\
(13.4961)\end{array}$ & $\begin{array}{l}-12.4345^{* *} \\
(3.8427)\end{array}$ & $\begin{array}{l}-1.6741 \\
(3.9943)\end{array}$ & $\begin{array}{l}-17.13 * * \\
(5.6747)\end{array}$ \\
\hline Supporter & $\begin{array}{l}6875.018 \\
(11750.06)\end{array}$ & $\begin{array}{l}987.5283 \\
(11445.36)\end{array}$ & $\begin{array}{l}2788.367 \\
(11200.37)\end{array}$ & $\begin{array}{l}-6674.504 \\
(11010.07)\end{array}$ \\
\hline Trades (experience) & $\begin{array}{l}119.5612 * \\
(60.2211)\end{array}$ & $\begin{array}{l}9.6357 \\
(36.3782)\end{array}$ & $\begin{array}{l}50.051 \\
(35.3785)\end{array}$ & $\begin{array}{l}79.5979 * \\
(33.9944)\end{array}$ \\
\hline \# of observations & 227 & 364 & 364 & 364 \\
\hline
\end{tabular}

Note: Standard errors in parenthesis (robust for heteroscedasticity for OLS); *significant at the 5\% level,

**significant at the $1 \%$ level. All player and transaction characteristics included as controls (only four reported).

Censored normal regression. The second column in Table 2 shows the results of a censored normal regression of the transfer price on the reserve price. The estimation is based on the full sample and controls for the censoring effect (i.e. for players that were not sold). The potential endogeneity of the reserve price is not considered. Again, the results indicate a positive and significant effect of the reserve price. ${ }^{8}$ As compared to the OLS estimation, however, the coefficient shrinks by more than 25 percent. Note

\footnotetext{
${ }^{8}$ The parameter estimates can be interpreted as population parameters, i.e. as effects for both censored and uncensored observations.
} 
also that the effects of total skill, age, form and wage point into the expected direction and are all significant.

In column III we include the interaction between the reserve price and the observation of a single bidder for the player as shown in Eq. (2). The interaction term measures the mechanical effect of reserve price setting in the second price auction, while the direct reserve price effect can be interpreted as a reference point effect. The estimation suggests that both effects are relevant. The reference point effect associated with a $€ 1$ increase in the reserve price leads to a 26 cent increase in the transfer price. For cases where there is only bidder, the mechanical effect leads to an additional 39 cents increase in the transfer price for these players. We cannot reject the hypothesis that the two effects are equally sized $(\mathrm{p}=0.21)$. The coefficients on the player attributes point in the expected direction, but the effect of the wage and the total skill are not significant.

Endogeneity of the reserve price. The regression in column IV considers the potential endogeneity of the reserve price. To obtain consistent estimates of the reserve price effect we apply the Smith-Blundell two-step procedure for endogeneity in censored regressions. In the first step we estimate a linear regression of the reserve price on all player characteristics and the three instruments: the tenure of the player in the seller's team, his improvement during his tenure, and whether he comes from the own youth of the seller. An F-test reveals a high partial correlation of our instruments with the reserve price $(\mathrm{F}(3,327)=4.88, \mathrm{p}=0.003)$. In the second step we calculate the residuals of the first step reduced-form OLS and include them in the censored regression of Eq. (2).

The results in column IV show a significant effect of the first-stage residuals, suggesting that the reserve price is indeed endogenous. Accounting for the endogeneity turns out to be crucial: the consistent estimate of the uninteracted reserve price now becomes insignificant. In contrast, our point estimate for the mechanical effect is virtually the same as the one in column III. The four key player characteristics have the expected effect and are highly significant.

The key finding of this last regression is that the reference point effect associated with the reserve price vanishes, once we control for endogeneity. The impact of the reserve on the transfer price is limited to those cases where there is only one bidder. In these situations, only the mechanical effect results in higher transfer 
prices. Replications of the results with alternative specifications show that the pattern of the reserve price effects from columns I to IV is robust. Using a different set of instruments ${ }^{9}$ or a logarithmic transformation of the dependent variable does not change the results.

\subsection{Manager behavior}

We included seller's experience and Hattrick Supporter membership into the reserve price regressions. One might conjecture that more experienced sellers are more successful selling their players at high price in a way that is not taken up in the control variables. They may, for instance, choose better timing within a trading day to post their players. Hattrick Supporters may be more active participants, who are better informed about the details of the game. They might therefore be also able to extract better prices, too.

Our results suggest that experienced traders indeed succeed to sell players at higher prices. Quantitatively, however, the effect is rather small: One more tradingexperience is associated with a $0.5 \%$ increase relative to the average transfer price. The finding in the basic regression is stable if we control for censoring and endogeneity in model IV. In contrast, the Hattrick Supporter status has no effect on transfer prices.

Buyer experience can only be included in the basic OLS because it is only observed for players that are sold. We did not include the variable in the above OLS regression to keep the set of explanatory variables constant across specifications. Running a separate OLS model including the variable, we find no significant effect of buyer experience $(\mathrm{p}>0.5)$. That is, while experienced sellers can extract slightly higher prices in our sample, experienced buyers seem to be unable to buy at cheaper prices.

As we have discussed in the context of endogeneity, the effect of reserve prices on transfer prices might be affected by the way the reserve prices are set. It is therefore useful to study how the selling managers set their reserve prices for players, and whether manager attributes have an effect on reserve price setting. The question can be answered through the first step regression of model IV, which estimates the determinants of the asking price. We find no effects of managers' experience on how

\footnotetext{
${ }^{9}$ If we use only subsets of the three instruments the first-stage partial F-statistic varies between 4.54 and 7.27 and our point estimates and standard errors in the main equation remain unchanged.
} 
they set reserve prices. The main determinants of the asking price, accounting together for more than $40 \%$ of the variation in asking prices, are the total skill of the player, the total skill improvement during the tenure on the seller's team, and the player's current wage. Consistent with economic intuition, total skill increases the reserve price and higher wage cost decrease the reserve price.

Interestingly, the improvement in total skill during tenure reduces the reserve price, controlling for the absolute level of total skill. For instance, a player with a total skill of 1000 who improved by 500 skill units during his tenure in the seller's team will be posted with a lower reserve price than a player with a total skill of 1000 who improved only by 100 units. As discussed in more detail in section 3, managers usually specialize on the training of one skill and sell those players which they train intensively to buy players for other positions. Players that receive training strongly improve their total skill index while others do not. A strong increase in total skill during tenure on a team therefore means that the player has explicitly been trained for selling him at the market. The observed effect indicates that such players 'for-themarket' are posted at lower reserve prices.

This observation is consistent with findings in the literature on loss aversion and reluctance to sell ("endowment effect"). For instance, in the housing market Genesove and Mayer (2001) show that houses held for resale by professional brokers are put on the market at lower reserve prices than houses held by occupant owners. Simonson and Drolet (2004) similarly show that people who have already decided to sell an item consider the market price as the relevant value, while those who are still uncertain whether they want to sell would rather consider their own personal needs and values. This effect can be interpreted in terms of the difference between players solely held for resale and those held for strategic reasons as part of the team: if market value is relevant for the former players the managers would rather let the auction determine the price; and if personal evaluations are relevant for the latter players the mangers would set a reserve price reflecting their evaluation. This is exactly what we observe.

\section{Discussion}

The impact of reserve prices on transfer prices has been an active research topic in both psychology and economics. While economists have focused on the 
effects of the auction mechanism (Riley \& Samuelson, 1981), psychologist are interested in the effects of reserve prices in the construction of valuations (Kristensen \& Gärling, 1997). We introduce an empirical model incorporating both a mechanical effect driven by the auction design and a psychological reference point effect. We test for both effects in a data set where there is symmetric information about 'product' attributes and thus no scope for quality signaling via reserve prices.

In the basic linear model that has been used in the literature, i.e. without distinguishing mechanical and psychological effects, we replicate the strong reserve price effect and find a similar effect size as earlier studies. When we distinguish between the mechanical and the psychological effect, we find evidence for both effects, even when we control for censoring. This suggests that the large impact of reserve prices reported in the literature could, at least partly, be due to mechanical effects of the second price auctions. Finally, when we account for the potential endogeneity of reserve prices, only the mechanical effect survives. Hence, we do not find evidence on reserve prices serving as reference points affecting bidder's uncertain private valuations. This finding could be explained by the absence of signaling motives in our context. In the presence of asymmetric information, signaling might thus be an important factor that contributes to a positive reserve price effect.

Comparing our study with other contributions in the literature shows additional factors that can explain the absence of reference point effects of the reserve price, and that hint at the importance of the auction institution in the interpretation of results from market studies. Hattrick auctions differ in two important respects from the second price auctions that were so far considered in the literature. First, Hattrick auctions are ascending open bid auctions while eBay uses a proxy auction where bidders specify a maximum willingness-to-pay. Hattrick therefore requires presence during the final stage of the auction while at eBay bids can be submitted beforehand, especially during a phase where no other bids have yet been submitted. This might amplify the effect of reserve prices. Second, in Hattrick the auction has a soft ending where the deadline is extended as long as there is active bidding; in eBay there is a hard deadline. Roth and Ockenfels (2002) and Ariely, Ockenfels and Roth (2005) have shown that such design features can interact with behavioral bidding strategies and can therefore lead to very different auction outcomes. In particular, a soft ending may lead to more competitive behavior during the final phase of the auction, making other persons' bids relatively more important compared to the reserve price. 
A further important feature, that is considered in the theoretical work in Rosenkranz and Schmitz (2007) and supported by the findings in Ariely and Simonson (2003), is the availability of independent economic evaluations (past market prices or list prices for new items) which can influence the strength of behavioral effects. The market participants in our Hattrick sample are very experienced with more than hundred trades on average on both sides of the market. In addition, they can apply various tools to evaluate the value of players for their team. This setting might reduce the influence of the reserve price as a reference point compared to casual buyers of consumer goods on eBay. More research comparing different auction mechanisms and degrees of value uncertainty seems therefore warranted to develop a taxonomy of market designs that foster or mitigate behavioral reserve price effects, respectively, and to better inform market designers and traders.

After having identified institutional aspects of auctions that can affect the relevance of behavioral factors and relating these to our findings, we will now consider the environment in which the Hattrick auctions are embedded. Hattrick auctions take place within a manager game with a virtual economy that works with virtual money. Although some participants spend real money to improve their performance in the game (by buying add-on programs which, e.g., support the evaluation of players), no real monetary incentives are involved.

In contrast to Psychologists, Economists have traditionally been skeptical in interpreting findings based on hypothetical incentives (Hertwig \& Ortmann, 2001; but see Read (2005) and Camerer \& Hogarth (1999) for deviating views). In particular, deviations from rationality are believed to be more likely in the absence of real monetary incentives (Camerer \& Hogarth, 1999). One might argue therefore that our setting provides an environment in which deviations from rationality, i.e. reference point effects on bids, would be expected to be even stronger than in real world auctions. Nevertheless, in our baseline model we find basically identical effects as studies that rely on the real incentives in eBay auctions. When we control for the impact of the auction design (the mechanical effect) and econometric problems, we find weaker evidence for behavioral biases.

Despite the missing monetary real incentives, we argue that Hattrick auctions are incentive compatible. Apart from the real monetary costs for additional programs, participation in Hattrick is - like for many other online games - quite costly in the sense of time invested. The economic constraints within the game structure lead to 
bankruptcy and thus elimination from the game. Receiving a new account to start from scratch can take several months. Castronova (2008) has studied whether economic constraints work in virtual environments with virtual money as they do in the real world. Experimentally comparing the effect of price differences between two identical virtual markets the author establishes basic laws of demand and price for the virtual economy. Castronova concludes that online games which are more complex than most laboratory settings but nevertheless allow for sufficient control can serve as platforms for economic and psychological research, including the possibility for experiments (see e.g. Nicklisch and Salz (2008), for a recent online field experiment).

\section{Conclusion}

Markets for football players represent highly organized institutions in which employees, i.e. players, are actually traded. In contrast to many product markets there are experts on both sides of the market and performance is easily observable and measured extensively through statistics. These features, which are mirrored in the Hattrick environment studied in this paper, are likely to reduce behavioral effects from reserve prices - in particular, if one considers the significant financial incentives at stake in modern professional football.

However, even with transparent performance measures as in the Hattrick game, uncertainty regarding the value of a player for the team and its future success remain. Consider, for instance, the possible acquisition of Frank Ribery by Barcelona C.F. how would Ribery interact with Lionell Messi? What are the financial consequences? Negative outcomes in the real world, either financially or in terms of team success, are highly observable and are scrutinized by the media, supporters, and sponsors (Lerner \& Tetlock, 1999). The combination of these latter factors suggests that behavioral effects in the setting of reserve prices and in their effect on transfer prices might still be relevant.

In the auctions of virtual players at the online platform Hattrick, we did not find evidence on a reference point effect from reserve prices. In contrast to the existing literature, we have estimated a model that separates psychological and mechanical effects of reserve prices on transfer prices. Controlling for censoring, we found evidence on both effects. Once we accounted for the likely endogeneity of reserve prices, however, the mechanical effect of the second price auction was 
observed, but no reference point effect. We have discussed several institutional aspects of auctions that may amplify or reduce reserve price effects. Real football players' markets are usually less structured than the auctions considered in the literature. To make more precise predictions concerning the economic and the reference point effects in real markets it would be useful to study the effects in more flexible market institutions. Kristensen and Gärling (1997) have shown that reserve price effects can also be observed in bilateral negotiations. Their paradigm could be extended to the simultaneous negotiations between seller and potential buyers observed for real world football players.

In our data we have observed that the way reserve prices are set by the selling managers is relevant for market outcomes. We have presented results that are informative about the factors that affect reserve price setting for football players. In particular, (young) players mainly seen as an investment might obtain lower prices than those well integrated in the core team, holding constant the quality of the player. The latter condition makes it difficult to identify this effect in the real world and suggests the study of more controlled environments.

Using more controlled laboratory experiments seems more generally a promising route in the study of reserve price effects in auctions. The existing evidence-including the one presented in this paper-derives from field data or field experiments. Although this evidence might have higher external validity than controlled laboratory results, it is potentially affected by confounding factors. More controlled experiments would also allow for a systematic variation of the design features that have been identified as potential determinants for the strength of behavioral effects, and for a systematic variation of the degree of valuation uncertainty. Clearly, more research on the role of reserve prices as reference points in different auctions formats is needed to improve predictions and to evaluate the efficiency of different designs. 


\section{Appendix}

A.1. Screenshot of a player on the transfer market

\section{hattrich}

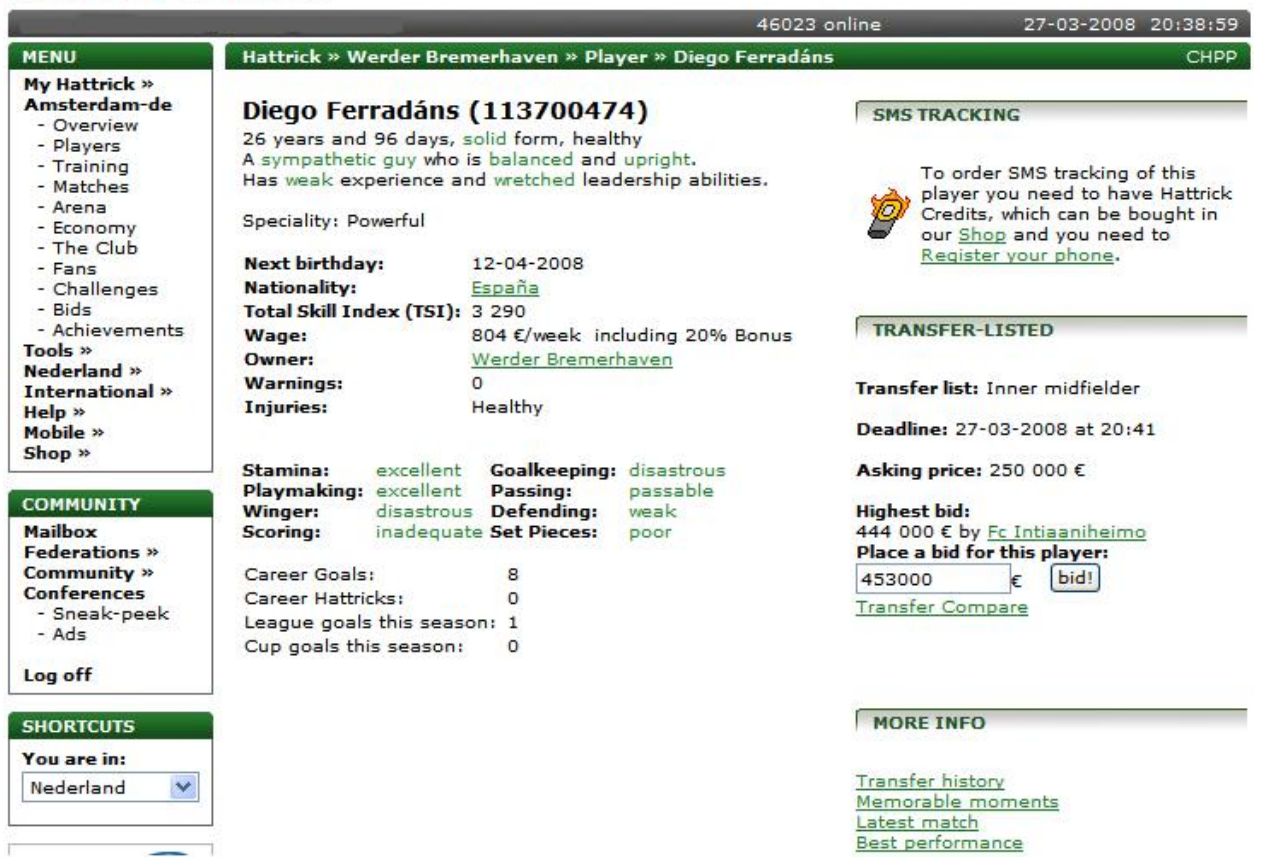

\section{A.2. List of variables}

\section{Player characteristics}

Total skill index, age, form, wage, winger, scoring, goalkeeping, passing, defending, set pieces, injured, experience, leadership, popularity, popularity $\times$ leadership (clown), stamina, career goals, aggressiveness, honesty, dummies for special skills (e.g. head)

\section{Transaction characteristics}

Data were collected on six days between July 11, 2007 and July 18, 2007. We include five day dummies and the previous market price for the player.

\section{Manager characteristics}

The seller's experience (trades) and Hattrick supporter status are included to study manager dependent effects. Buyer's experience is studied in one specification.

\section{Player-seller interaction characteristics}

Tenure of the player on the team, total skill improvement during tenure, descendant from own youth team or original player 


\section{References}

Ajalin, P., Granö, T. \& Nyberg, K. (2004). Betting on virtually simulated gamesCase Hattrick. In R. Sarvas, M. Turpeinen \& S. Jokela (Eds.). New business in computer-mediated communities. Technical report, HUT Software Business and Engineering Institute, Helsinki.

Ariely, D. \& Simonson, I. (2003). Buying, bidding, playing or competing? Value assessment and decision dynamics in online auctions. Journal of Consumer Psychology, 13, 113-123.

Ariely, D., Ockenfels, A. \& Roth, A. E. (2005). An experimental analysis of ending rules in Internet auctions. RAND Journal of Economics, 36, 890-907

Bajari, P. \& Hortacsu, A. (2003). The winner's curse, reserve prices and endogenous entry: Empirical insights from eBay auctions. RAND Journal of Economics, 34, $329-355$.

Bleichrodt, H. (2007). Reference-dependent utility with shifting reference points and incomplete preferences. Journal of Mathematical Psychology, 51, 266-276.

Camerer, C. and Hogarth, R. (1999). The Effect of Financial Incentives in Experiments: A Review and Capital-Labor-Production Framework. Journal of Risk and Uncertainty, 19, 7-42.

Castronova, E. (2008). A Test of the Law of Demand in a Virtual World: Exploring the Petri Dish Approach to Social Science. Working paper 2355, CESifo, Munich.

Englmaier, F. \& Schmöller, A. (2008). Does bidding for multi-attribute goods reflect all relevant information? Field evidence from online gaming. Working paper, Munich.

Genesove, D. \& Mayer, C. (2001). Loss aversion and seller behavior: Evidence from the housing market. Quarterly Journal of Economics, 116, 1233-1260.

Hertwig, R. and Ortmann, A. (2001). Experimental practices in economics: A methodological challenge for psychologists? Behavioral and Brain Sciences, $24,393-451$.

Hoppe, T. \& Sadrieh, A. (2007). An experimental assessment of confederate reserve price bids in online auctions. Working paper, Magdeburg.

Kahneman, D. (2003). Mapping bounded rationality. American Psychologist, 58, $697-720$. 
Kamins, M. A., Drèze, X. \& Folkes, V. S. (2004). Effects of seller-supplied prices on buyers' product evaluations: Reference prices in an internet auction context. Journal of Consumer Research, 30, 622-628.

Kristensen, H. \& Gärling, T. (1997). Determinants of buyers' aspiration and reserve price. Journal of Economic Psychology, 18, 487-503.

Lerner, J. S. \& Tetlock, P. E. (1999). Accounting for the effects of accountability. Psychological Bulletin, 125, 255-275.

Lin, C.-H., Huang, W.-H., \& Zeelenberg, M. (2006). Multiple reference points in investor regret. Journal of Economic Psychology, 27, 781-792.

Nicklisch, A. \& Salz, T. (2008). Reciprocity and status in a virtual field experiment. Working Paper 08/37, Max Planck Institute for Research on Collective Goods.

Read, D. (2005). Monetary Incentives, What Are They Good For? Journal of Economic Methodology, 12, 265-276.

Resnick, P., Zeckhauser, R., Swanson, J., \& Lockwood, K. (2006). The Value of Reputation on eBay: A controlled Experiment. Experimental Economics, 9, 79-101.

Riley, J. G. \& Samuelson, W. F. (1981). Optimal Auctions. American Economic Review, 71, 381-392.

Rosenkranz, S. \& Schmitz, P. W. (2007). Reserve prices in auctions as reference points. Economic Journal, 117, 637-653.

Roth, A. E. \& Ockenfels, A. (2002) Last-minute bidding and the rules for ending second-price auctions: Evidence from eBay and Amazon auctions on the Internet. American Economic Review, 92, 1093-1103.

Sayman, S. \& Öncüler, A. (2005). Effects of study design characteristics on the WTA-WTP disparity: A meta analytical framework. Journal of Economic Psychology, 26, 289-312.

Schmidt, U. (2003). Reference dependence in cumulative prospect theory. Journal of Mathematical Psychology, 47, 122-131.

Simonson, I. \& Drolet, A. (2004). Anchoring Effects on Consumers' Willingness-toPay and Willingness-to-Accept. Journal of Consumer Research, 31, 681-690.

Smith, R. \& Blundell, R. (1986). An exogeneity test for a simultaneous equation Tobit model with an application to labor supply. Econometrica, 54, 679-685. 
Stern, B. B. \& Stafford, M. R. (2006). Individual and social determinants of winning bids in online auctions. Journal of Consumer Behaviour, 5, 43-55.

Wooldridge, J. M. (2002). Econometric analysis of cross section and panel data. MIT Press: Cambridge, MA. 